\title{
ENSINO MÉDIO E INTERDISCIPLINARIDADE: REFLEXÕES SOBRE O ENSINO DE SOCIOLOGIA
}

\author{
J. G. S. A. LIMA', J. S. G. COSTA ${ }^{2}$ e M. M. C. A PERNAMBUCO ${ }^{3}$ \\ 1,2,3 Universidade Federal do Rio Grande do Norte \\ E-mail: gllauco_ufrn@yahoo.com.br ${ }^{1}$
}

Artigo submetido em março/2012 e aceito em maio/2012

\section{RESUMO}

A interdisciplinaridade constitui debate no meio educacional há bastante tempo. No âmbito dessa discussão, o imperativo explicitado por grande parte dos responsáveis pela organização curricular é o da necessidade da elaboração de práticas pedagógicas interdisciplinares. Os discursos, ao que parecem, são sempre os mesmos: "É preciso trabalhar de modo interdisciplinar"; "A interdisciplinaridade constrói um conhecimento mais completo"; ou ainda, "Nossa escola trabalha através de projetos interdisciplinares". Mas, afinal, o que é interdisciplinaridade? Qual a sua importância para a reconfiguração do aprender e do ensinar? Qual a sua relevância no interior das práticas educativas desenvolvidas no Ensino Médio? Estes são alguns dos questionamentos motivadores deste trabalho, o qual se debruça, especialmente, sobre a análise da integração dos conhecimentos sociológicos e os de outras disciplinas integrantes do currículo do Ensino Médio, com vistas à tecitura de considerações críticas sobre a problemática em apreço. Trata-se de um estudo metodologicamente situado na reflexão qualitativa e quantitativa dos resultados do préteste da pesquisa "A Situação do Ensino de Sociologia na Escola de Ensino Médio do Rio Grande do Norte/Brasil", realizada pelo Grupo de Pesquisa Cultura Política e Educação, do Departamento de Ciências Sociais da Universidade Federal do Rio Grande do Norte (UFRN), em parceria com a Sociedade Brasileira de Sociologia (SBS) e o Laboratório de Pesquisa em Ciências Sociais (LAPIS-UFRN), em ocasião do XIV Congresso Nacional dos Sociólogos, do VII Encontro Nacional de Cursos de Ciências Sociais e do I Seminário Nacional de Educação em Ciências Sociais, realizados em abril de 2008. Traz como considerações gerais a necessidade de uma reorganização curricular tanto dos cursos de formação de professores quanto do modo como se organiza o Ensino Médio, de modo a romper com a distribuição de disciplinas por departamentos isolados e com o ensino de professores que repetem comportamentos pedagógicos sem a necessária reflexão.

PALAVRAS-CHAVE: Escola, Ensino Médio, Ensino de Sociologia, Interdisciplinaridade, Organização curricular.

\section{HIGH SCHOOL AND INTERDISCIPLINARITY: REFLECTIONS ON THE TEACHING OF SOCIOLOGY}

\begin{abstract}
The Interdisciplinarity is debate in educational environment for a long time. In the context of this discussion, the need expressed by most responsible for curriculum organization is the need for the elaboration of interdisciplinary educational practices. The speeches, they seem, are always the same: "you have to work interdisciplinary"; "Interdisciplinarity constructs a fuller knowledge"; or even, "Our school works through interdisciplinary projects". But, after all, what is interdisciplinarity? What is its importance to the reconfiguration of the learning and teaching? What is its relevance within educational practices developed in high school? These are some of the questions motivating this work, which focuses especially on the analysis of the integration of sociological knowledge and of other subjects members of the high school curriculum, with a view to tecitura critical considerations on the problems at hand. It
\end{abstract}

is located in the reflection study methodologically qualitative and quantitative of the pre-test results of searching "the situation of teaching sociology at the high school of Rio Grande do Norte-Brazil", carried out by the research group Culture politics and education, Department of social sciences of the Federal University of Rio Grande do Norte (UFRN), in partnership with the Sociedade Brasileira de Sociologia (SBS) and the Social Science Research Laboratory (LAPIS-UFRN)on the occasion of the XIV National Congress of sociologists, the VII national meeting of Social Sciences courses and I national seminar of education in social sciences, held in April 2008. Brings as a general reorganization of both curricular teacher training courses on how to organize the high school, so as to break with the distribution of subjects by isolated departments and with the teaching of teachers who are teaching behaviors without the necessary reflection.

KEY-WORDS: High School, Teaching sociology, Interdisciplinarity, Curricular organization. 


\section{ENSINO MÉDIO E INTERDISCIPLINARIDADE: REFLEXÕES SOBRE O ENSINO DE SOCIOLOGIA}

\section{PRIMEIRAS PALAVRAS...}

Atualmente, é quase impossível não encontrarmos nas propostas de ensino, bem como nos Projetos Políticos Pedagógicos (PPP's) de escolas e de cursos universitários, a ideia de que é preciso a elaboração de práticas pedagógicas interdisciplinares que envolvam o percurso formativo dos estudantes. Somada a essa constatação, percebemos que a crescente banalização do termo "interdisciplinaridade", pelos próprios especialistas do ensino, acabou por transformálo numa espécie de "jargão pedagógico", ou seja, em mais uma argumentação retórica presente no cenário educativo que impede a compreensão do movimento interdisciplinar como uma prática que reclama reflexão, planejamento e empenho coletivo para a concretização das ações educativas.

Em termos gerais, a interdisciplinaridade busca a construção de um diálogo entre as diversas áreas do saber, tendo como objetivo precípuo o desencadeamento de análises pluridimensionais da realidade em sua grandeza e complexidade. Isso não quer dizer, contudo, que a ideia de uma proposta interdisciplinar defenda a anulação dos marcos epistemológicos dos setores do conhecimento. É preciso deixar claro que, mesmo amparada numa concepção dialógica da relação entre os saberes, a interdisciplinaridade, ao contrário do que muitos pensam, não é uma prática que visa a eliminação dos conhecimentos disciplinares, pois "respeita a especificidade de cada área do conhecimento, isto é, a fragmentação necessária no diálogo inteligente com o mundo [...]" (DELIZOICOV E ZANETIC, 1993, p. 13). Nessa linha argumentativa, os Parâmetros Curriculares Nacionais para o Ensino Médio (PCNEM) acrescentam que

a interdisciplinaridade não dilui as disciplinas, ao contrário, mantém sua individualidade. Mas integra as disciplinas a partir da compreensão das múltiplas causas ou fatores que intervêm sobre a realidade e trabalha todas as linguagens necessárias para a constituição de conhecimentos, comunicação e negociação de significados e registro sistemático dos resultados (BRASIL, 2002, p. 89).

Aprofundando essa visão, Bossa (2007) esclarece que a interdisciplinaridade não é a mera aglutinação de várias perspectivas analíticas sobre um tema ou uma problemática da realidade, mas sim o movimento que oportuniza a construção de um novo conhecimento, que, embora tenha nascido a partir da contribuição das diversas disciplinas envolvidas na análise, não pertence a nenhuma delas, sendo, por isso mesmo, um conhecimento assentado em novas bases epistemológicas. Eis aí, segundo esta autora, a condição essencial de toda ação interdisciplinar. Reforçando seu raciocínio, Nadia Bossa recorre a Barthes $(1998)^{1}$, que diz:

o interdisciplinar, de que tanto se fala, não está em confrontar disciplinas já constituídas das quais, na realidade, nenhuma consente em abandonar-se. Para se fazer interdisciplinaridade, não basta tomar um assunto (um tema) e convocar em torno duas

\footnotetext{
${ }^{1}$ BARTHES, R. O rumor da língua. São Paulo: Brasiliense, 1998.
} 
ou três ciências. A interdisciplinaridade consiste em criar um objeto novo que não pertença a ninguém (BARTHES, 1998, p. 99, grifo no original, apud BOSSA, 2007, p. 35).

Diante disso, e no que diz respeito ao labor pedagógico e ao conhecimento construído no âmbito formal (escolas e universidades, particularmente), a concepção de trabalho interdisciplinar "[...] pressupõe um procedimento que parte da idéia de que as várias ciências deveriam contribuir para o estudo de determinados temas que orientariam todo o trabalho escolar" (DELIZOICOV E ZANETIC, 1993, p. 13), propiciando, assim, a tecitura de um saber que provém das várias disciplinas, mas que, ao mesmo tempo, não pertence a nenhuma delas, como faz crer Bossa (2007). Além disso, constrói-se um conhecimento mais próximo da multidimensionalidade do real capaz de suscitar compreensões cada vez mais amplas em torno das problemáticas que dele surgem.

Nesse raciocínio, o saber interdisciplinar a ser elaborado nos espaços escolares e universitários deve ter por princípio a formação, nos sujeitos, de uma nova forma de organização do pensamento, ou seja, a construção de uma postura cognitiva omnilateral apta a melhor interpretar a realidade e atuar sobre ela. Isso implica na ressignificação dos atos de aprender e de ensinar, posto que reconfigura a base epistemológica sobre a qual se assentam estes dois processos.

Numa perspectiva exclusivamente disciplinar, o aprender e o ensinar subordinam-se a práticas mecânicas de transmissão e acúmulo de informações, as quais em nada contribuem para o desenvolvimento, nos estudantes, de um pensar crítico-atuante no interior da realidade social e natural em que vivem, posto que o ato cognoscente ampara-se naquilo a que Paulo Freire (2005) denominou de "educação bancária". Ademais, a ação de construção do conhecimento perde a sua identidade relacional e interacional, enclausurando-se nos rígidos limites de certo campo epistemológico. Assim, fica obscurecido o fato de que

conhecer é apreender o mundo em suas relações, um processo necessariamente dinâmico, no qual, através das ações físicas e mentais, os diferentes sujeitos constroem, em uma interação coletiva, novas formas de se relacionar e compreender o mundo (PERNAMBUCO, 1993, p. 24, grifo no original).

A contribuição de Pernambuco (1993) nos é pertinente por possibilitar a visualização do aspecto relacional e interacional em que se fundamentam as práticas de ensino e de aprendizagem numa visão interdisciplinar. Nesta, o trabalho pedagógico ganha em riqueza e em complexidade ao oportunizar reflexões abrangentes acerca de determinado objeto de análise. Tal postura se ergue no solo da incompletude dos saberes e na afirmação de que a realidade é muito complexa para caber em uma única perspectiva interpretativa dos fenômenos naturais e humanos. Sobre isso, Fazenda (2000) acrescenta que o pensamento interdisciplinar parte do princípio de que nenhum conhecimento é absolutamente completo, daí porque o diálogo entre as diversas lógicas cognitivas seja uma condição indispensável para a elaboração de um saber mais inteiro.

O aprender e o ensinar, dentro dessa concepção, admitem outros significados, pois começam a ser compreendidos como atividades interdependentes de ação-reflexão-ação (FREIRE, 2005), incluindo-se também a dimensão do engajamento em face de um projeto coletivo 
de interpretação da realidade nascido da confluência entre diferentes disciplinas, no qual cada uma, a seu modo, oferece "agulhas intelectuais" para a costura de uma "colcha intercognitiva". Assim, os processos de ensino e de aprendizagem se inserem no âmbito de um novo prisma epistemológico que sustenta a ideia de que

[...] o pensar interdisciplinar parte do princípio de que nenhuma forma de conhecimento é em si mesma racional. Tenta, pois, o diálogo com outras formas de conhecimento, deixando-se interpenetrar por elas. Assim, por exemplo, aceita o conhecimento do senso comum como válido, pois é através do cotidiano que damos sentido às nossas vidas. Ampliado através do diálogo com o conhecimento científico, tende a uma dimensão utópica e libertadora, pois permite enriquecer nossa relação com o outro e com o mundo. (FAZENDA, 2000, p. 17).

Nesses termos, ancorada numa nova concepção de ensino e de aprendizagem, a dinâmica pedagógica da escola e da universidade é redimensionada, abrindo possibilidades para múltiplas formas de trabalho educativo, começando pelos projetos integradores, os quais oportunizam diversas formas de trabalho educativo: as aulas de campo, as aulas expositivo-dialogais, seminários e os cines-discussão interdisciplinares, por exemplo. Assim, ao se começar por uma temática aglutinadora constroem-se as pontes para a abordagem interdisciplinar no âmbito do processo formativo de professores e estudantes.

Levando em consideração o que foi dito anteriormente acerca das contribuições trazidas ao trabalho pedagógico pela concepção interdisciplinar, cabe analisar, antes de adentramos na reflexão sobre a integração dos conhecimentos sociológicos e os de outras disciplinas do Ensino Médio, se a universidade propicia aos futuros professores um amparo teórico-prático para o desenvolvimento de uma ação educativa fundamentada nos princípios da interdisciplinaridade.

\section{INTERDISCIPLINARIDADE, TRABALHO PEDAGÓGICO E FORMAÇÃO DE PROFESSORES: ALGUMAS REFLEXÕES}

À primeira vista, documentos oficiais como a Lei de Diretrizes e Bases da Educação Nacional (Lei $n^{\circ}$ 9.394/96) e as Diretrizes Curriculares Nacionais para a Formação de Professores da Educação Básica (2002), nos dão indícios para compreendermos a interdisciplinaridade como um elemento necessário para a formação de professores. Dizem esses documentos:

Art. 61. A formação de profissionais da educação, de modo a atender aos objetivos dos diferentes níveis e modalidades de ensino e às características de cada fase do desenvolvimento do educando, terá como fundamentos: ${ }^{2}$

I - a associação entre teorias e práticas, inclusive mediante a capacitação em serviço. (BRASIL, 2006, p. 36, grifo nosso).

Art. 11. Os critérios de organização da matriz curricular, bem como a alocação de tempos e espaços curriculares se expressam em eixos em torno dos quais se articulam dimensões a serem contempladas, na forma a seguir indicada: ${ }^{3}$

\footnotetext{
${ }^{2}$ Em função das finalidades deste trabalho, suprimimos o inciso II do Art. 61 da LDBN/1996.

${ }^{3}$ Com a mesma razão da nota de rodapé acima, suprimimos os incisos I, II, IV, V e o parágrafo único do Art. 11 das Diretrizes Curriculares Nacionais para a Formação de Professores da Educação Básica.
} 
III - eixo articulador entre disciplinaridade e interdisciplinaridade;

VI - eixo articulador das dimensões teóricas e práticas (BRASIL, 2002, p. 5).

Da mesma forma que os documentos citados acima, todos os outros, de caráter mais teórico-conceitual e de orientação didático-pedagógica, como os PCN's (Ensino Fundamental e Médio) e os PCN's+, por exemplo, atentam para a necessidade de práticas interdisciplinares que busquem a elaboração de um conhecimento escolar capaz de oferecer discussões satisfatórias para problemáticas cada vez mais complexas do mundo contemporâneo, para as quais uma visão estritamente disciplinar do conhecimento não consegue iluminar.

Assim, baseados nas leis que regem o ensino, bem como nos documentos orientadores para a elaboração curricular, gestores das instituições escolares passam a exigir de professores, de coordenadores pedagógicos e de outros profissionais envolvidos com os processos de ensino e de aprendizagem, competências e habilidades que, nos cursos de formação docente, ainda estão concentradas, quase que exclusivamente, ao nível da discussão teórica, o que provoca grande desorientação quando tais competências e habilidades são requeridas na prática educativa propriamente dita.

Não queremos dizer, com isso, que não haja, no âmbito dos cursos de formação de professores, um sólido debate teórico-conceitual, mas sim que teoria e prática possam dialogar e constituir um par dialético, de modo que a primeira possa melhor iluminar a segunda e esta, por sua vez, questionar a teoria com vistas a ampliá-la. O que estamos criticando, precisamente, é o descompasso entre a formação universitária dos professores e a exigência que a estes se faz quanto ao desenvolvimento de atividades educativas interdisciplinares em suas práticas docentes.

Diante disso, se faz oportuno reconhecermos que no momento da formação inicial dos professores não lhes são oportunizados, em função da não mudança da organização curricular a que estão submetidos, espaços nos quais o fazer interdisciplinar possa ser vivenciado em termos de planejamento e execução de propostas de ensino assentadas no diálogo entre as várias disciplinas. Nesses termos, como esperar que os profissionais do ensino desenvolvam tais competências e habilidades em seus alunos se na formação universitária a discussão teórica sobre interdisciplinaridade sobrepuja o seu fazer prático?

Em nosso entender, isso configura um paradoxo que precisa de uma problematização mais criteriosa, tendo em vista que o ato de educar também diz respeito à formação de sujeitos humanos que não estão presos em gaiolas ou cercados por muros instransponíveis, uma vez que estão mergulhados numa realidade altamente complexa, de onde irradia uma multiplicidade de problemas que necessitam de linguagens, códigos, significados e conteúdos igualmente plurais para sua compreensão, pois conforme assinala Antoni Zabala, "todo conteúdo, por mais específico que seja, sempre está associado e portanto será aprendido junto com conteúdos de outra natureza" (ZABALA, 1998, p. 40).

Apesar disso, não desconhecemos que a ênfase dada por nossas universidades à abordagem disciplinar na formação docente possa vir a possibilitar um maior domínio de área, garantindo competências e habilidades no âmbito de certos limites epistemológicos. Contudo, essa ênfase acaba por dificultar a articulação de várias disciplinas e, com isso, prejudica-se a visualização da riqueza do mundo em termos de complexidade epistêmica, dificultando, de igual modo, a construção de uma perspectiva analítica capaz de amalgamar diferentes conhecimentos 
para a interpretação e a intervenção no real. É importante deixar claro, mesmo considerando o conteúdo de nossa crítica, que não negligenciamos o tratamento disciplinar, até porque

[...] as disciplinas são plenamente justificadas intelectualmente, contanto que elas guardem um campo de visão que reconheça e compreenda a existência de ligações de solidariedade. E mais, elas só são plenamente justificadas se não ocultam as realidades globais (MORIN, 1999, p. 76, grifo nosso).

No entanto, também não negligenciamos que se faz necessária uma contundente reflexão sobre o modo como se educa e como se constrói conhecimento nos espaços universitários, pois a maneira como os futuros professores são formados incide diretamente em suas práticas educativas posteriores. Convém perceber, nesse sentido, que muitos licenciados são ou foram formados em moldes tradicionais, o que provoca a ritualização e a cristalização, no recinto das escolas nas quais lecionam ou nas quais lecionarão, das práticas educativas vivenciadas nas universidades. Como consequência, se gera e se reproduz uma educação que imerge os estudantes numa cultura escolar alheia aos nexos que os fenômenos naturais e socioculturais possuem entre si.

Nesse contexto, fica difícil formar professores que pensem e pratiquem interdisciplinaridade quando a mentalidade acadêmica, refletida na organização dos currículos de seus cursos universitários, ainda está acostumada a ver o mundo sob perspectivas teóricoconceituais isoladas, como se a complexidade da realidade fosse alardeada através de um único "alto-falante argumentativo".

Não basta sustentarmos o discurso que conclama a interdisciplinaridade como fundamento necessário para que os estudantes das Licenciaturas e da Educação Básica, alvos e sujeitos de nossas intenções educativas, apreendam o mundo sob facetas plurais para a compreensão da realidade. É preciso que a estrutura sobre a qual se erguem as propostas curriculares esteja inserida nesta nova forma de encarar a construção do conhecimento, que não é, diga-se de passagem, uma metodologia de ensino, mas uma nova organização epistemológica que em muito pode contribuir para a reorganização da escola/universidade e de suas muitas experiências formativas.

Precisamos repensar as bases nas quais se erguem a formatação curricular dos cursos de licenciatura. Não cabe mais relegar a formação pedagógica dos futuros licenciados ao final de seus cursos, pois além de não construírem conhecimentos teórico-conceituais sólidos sobre os fundamentos da educação, a prática educativa fica comprometida em função do pouquíssimo tempo a ela dedicada. Defendemos que em diálogo com a aprendizagem dos conhecimentos específicos da área em que se inserem os estudantes, estes devem ter contato com os conhecimentos pedagógicos que lhes deem suporte às suas atuações docentes posteriores à conclusão da licenciatura.

Em termos mais claros, defendemos que a formação pedagógica do futuro professor deve estar presente desde a sua entrada no curso de licenciatura, seja de química, física, matemática, sociologia ou filosofia, por exemplo. Caso contrário, os cursos de licenciatura formarão, paradoxalmente, bacharéis ao invés de professores.

No que se refere à interdisciplinaridade no interior da universidade, os cursos de formação docente precisam atentar para uma reorganização de suas bases curriculares que 
inclua também a efetivação de espaços através dos quais estudantes de vários campos disciplinares possam dialogar e observar, coletivamente, que as perspectivas epistemológicas de suas áreas de origem não dão conta satisfatoriamente do caráter integral das problemáticas que emergem do mundo natural e humano.

Dessa maneira, corroboramos a ideia de que os estudantes necessitam viver espaços plurais de ação-reflexão-ação para reconhecerem que seus conhecimentos disciplinares são sempre parciais, tendo em vista que a possibilidade de análise fixada por sua esfera epistemológica é igualmente parcial (PIERSON et al, 2008).

Nesse viés, e ainda ancorados nas contribuições de Pierson et al (2008), acreditamos que uma prática interdisciplinar no ensino do conhecimento científico pode oportunizar ao futuro docente elementos teórico-práticos necessários à construção, em si mesmo e nos recintos escolares em que atuará, de uma mentalidade capaz de compreender problemas reais a partir de suas complexidades e contextos sociais concretos e, com isso, também pensar, em diálogo com seus alunos, soluções e alternativas para tais problemas de maneira igualmente integral.

Convém ressaltar, como base nisto, que a emergência deste pensar interdisciplinar não acontece deslocada da necessária mudança no paradigma curricular que ainda predomina nos cursos de formação universitária. Acreditar que sim é corroborar medidas paliativas que não tocam no principal aspecto do problema, que é, conforme insistimos, a reflexão em torno da indispensável transformação dos currículos universitários e da base epistemológica em que ainda se fundam.

Portanto, observamos que o lugar da interdisciplinaridade nos cursos de formação de professores se constitui na dimensão do "inédito-viável" ${ }^{4}$ e da "ação-editanda" ${ }^{5}$ Freire (2005), incorporando um viés teórico-epistemológico praticável no âmbito da reestruturação dos currículos das licenciaturas capaz de fomentar novos comportamentos gnosiológicos, como também incentivar uma positiva transgressão cognitiva que abra possibilidades concretas para o combate não apenas da extremada fragmentação dos saberes, mas também faça enxergar um horizonte a ser trilhado para a formação de sujeitos humanos cada vez mais críticos, participativos e autônomos diante das realidades que os circunda, caso contrário, o discurso sobre a interdisciplinaridade continuará a ser mais uma retórica argumentativa no rol das muitas que já existem em nosso cenário educacional.

\section{A INTERDISCIPLINARIDADE E O CONHECIMENTO SOCIOLÓGICO NO ENSINO MÉDIO}

As considerações sobre a questão da interdisciplinaridade e o ensino da Sociologia na escola de nível médio estão amparadas na reflexão qualitativa e quantitativa dos resultados do pré-teste ${ }^{6}$ da pesquisa "A Situação do Ensino de Sociologia na Escola de Ensino Médio do Rio

\footnotetext{
${ }^{4}$ No pensamento paulofreireano, o "inédito viável” diz respeito a soluções praticáveis não percebidas. Soluções que advêm da necessidade da superação das "situações limites", as quais, em linhas gerais, são aquelas situações que impedem o ser humano de realizar sua "vocação ontológica", isto é, a de ser mais no sentido de sua incompletude histórico-ontológica.

5 Refere-se à ação possibilitadora do "inédito viável”. Ação “[...] cuja viabilidade antes não era percebida” (FREIRE, 2005, p. 124).

${ }^{6}$ Pré-teste respondido por apenas 11 professores. Para maiores esclarecimentos, consultar Gomes (2008).
} 
Grande do Norte/Brasil”" , realizada pelo Grupo de Pesquisa Cultura Política e Educação, do Departamento de Ciências Sociais da Universidade Federal do Rio Grande do Norte (UFRN), em parceria com a Sociedade Brasileira de Sociologia (SBS) e o Laboratório de Pesquisa em Ciências Sociais (LAPIS-UFRN), em ocasião do XIV Congresso Nacional dos Sociólogos, do VII Encontro Nacional de Cursos de Ciências Sociais e do I Seminário Nacional de Educação em Ciências Sociais, realizados em abril de 2008, na cidade de Natal/RN.

Dentre os questionamentos presentes no pré-teste aplicado aos professores da disciplina Sociologia, um relacionava-se diretamente com a temática da interdisciplinaridade, indagando, especificamente, sobre como o professor(a) fazia a integração da Sociologia com as outras disciplinas do currículo do Ensino Médio. As respostas estão assinaladas no Gráfico 1 a seguir:

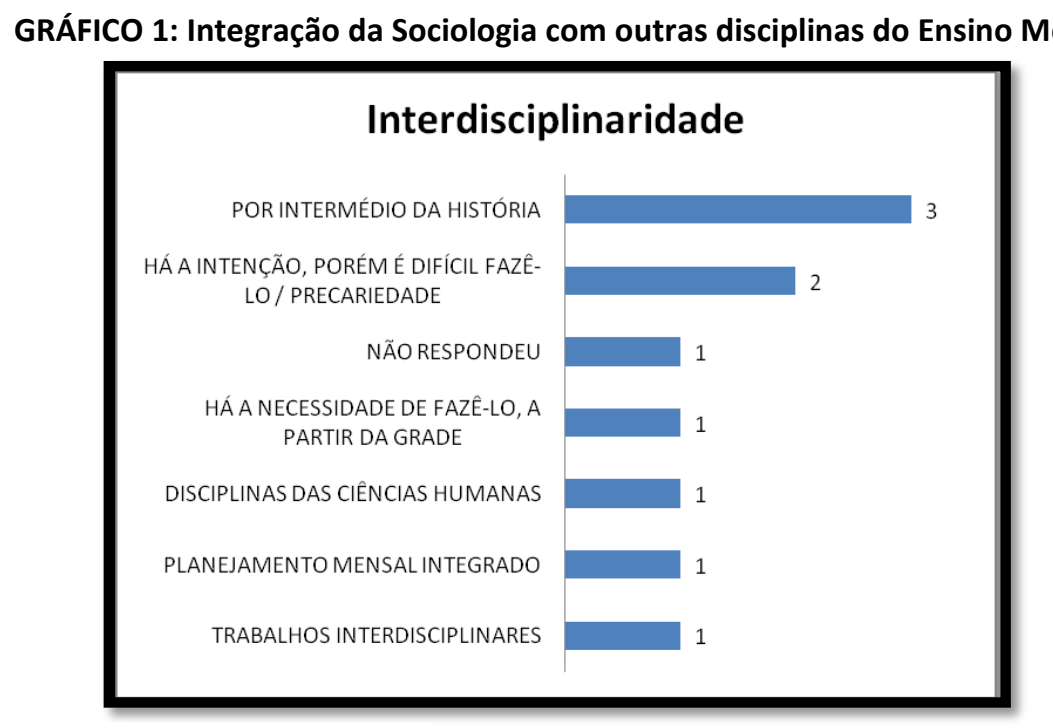

Fonte: Gomes (2008).

Embora reconheçamos que os dados do pré-teste não revelem satisfatoriamente como os professores de Sociologia do Ensino Médio realizam a relação do conhecimento sociológico com o das outras disciplinas, eles nos dão indicativos, mesmo que incipientes, para verificarmos que há certa desorientação destes professores quanto ao estabelecimento de práticas educativas interdisciplinares no âmbito das aulas de Sociologia.

A "realidade" lida nas respostas destes 11 professores nos permite ratificar nossa argumentação no que diz respeito à necessidade da reestruturação epistemológica dos currículos dos cursos de formação de professores. A dimensão vaga e genérica das respostas apresentadas pode indicar, dentre outros aspectos, a ausência de atividades práticas no tocante ao exercício da interdisciplinaridade quando da formação inicial destes professores.

O estabelecimento da interdisciplinaridade no Ensino Médio depende, em grande medida, do contato que têm os futuros docentes com atividades e problemáticas que reclamem um tratamento interdisciplinar no momento de suas formações em nível superior. Ademais, se não se muda a base epistemológica sobre a qual se assentam os currículos das licenciaturas, os professores da Educação Básica continuarão a desenvolver práticas educativas compartimentadas

\footnotetext{
${ }^{7} \mathrm{O}$ detalhamento dos resultados da referida pesquisa exploratória estão disponíveis no site da Revista Inter-Legere (http://www.cchla.ufrn.br/interlegere), n³ (Julho/Dezembro de 2008).
} 
e descontextualizadas que em nada contribuirão para a formação integral dos estudantes, ou seja, não garantirão uma educação que ajude os estudantes a compreenderem a complexidade do mundo em que vivem.

Assim, a possível desorientação dos professores de Sociologia quanto ao estabelecimento de práticas educativas interdisciplinares no âmbito de suas aulas pode representar um problema epistemológico não desta disciplina em particular, mas do universo cognitivo em que está inserida. Concordamos que uma reformulação da lógica de produção de conhecimento na universidade pode oportunizar igual reformulação no modo como se constrói conhecimento no âmbito da Educação Básica e, nesse sentido, ajudar aos professores de Sociologia, de Filosofia, de Geografia, de História, ou de qualquer outro campo do saber, a desenvolverem práticas pedagógicas coerentes com a multidimensionalidade dos fenômenos naturais e humanos.

\section{CONSIDERAÇÕES FINAIS}

Finalizando nossas observações, cabe refletirmos sobre uma última pergunta: por que a prática da interdisciplinaridade ainda é algo incipiente tanto nos cursos de formação de professores como nas escolas de Educação Básica?

Em grande parte, porque os esforços direcionados à prática da interdisciplinaridade ainda se configuram numa espécie de paliativo refletido através de ações isoladas que não tocam no essencial, que é, consoante acreditamos, a necessária mudança das bases epistemológicas dos currículos dos cursos de formação de professores que incida numa reformulação nos currículos dos vários níveis de ensino constituintes da Educação Básica.

É preciso uma nova reconfiguração para nossos currículos (universitários e escolares) que rompa com a distribuição de disciplinas por departamentos acadêmicos isolados e com o ensino de professores que repetem comportamentos pedagógicos sem a necessária reflexão.

Precisamos, nesse sentido, da criação de alternativas político-pedagógicas pelas quais os currículos (de qualquer nível de ensino) possam oportunizar ao aluno ser sujeito de uma aprendizagem que se realiza a partir de interações cognitivas múltiplas, de modo que isso venha possibilitar a ressignificação do processo de aprender-ensinar-aprender.

Assim, se faz urgente chamar ao debate as grandes temáticas que oportunizam a articulação teoria-prática e que reclamam por um trabalho conjunto entre disciplinas e entre os sujeitos dos processos de ensino e de aprendizagem. Apenas desse modo poderemos contribuir para uma reestruturação curricular dos cursos universitários e das escolas de Educação Básica que esteja assentada na heterogeneidade, na processualidade e que represente um desafio coletivo para alunos e professores diante da compreensão da complexa dinâmica natural e societária que os circunda.

\section{REFERÊNCIAS BIBLIOGRÁFICAS}

1. BOSSA, Nadia A. A psicopedagogia no Brasil: contribuições a partir da prática. 3. ed. Porto Alegre: Artmed, 2007. 
2. BRASIL. Diretrizes Curriculares Nacionais para a formação de Professores da Educação Básica. Brasília, 2002.

3. Lei de Diretrizes e Bases da Educação. 3. ed. Brasília: Senado Federal, Subsecretaria de Edições Técnicas, 2006.

4. Parâmetros Curriculares Nacionais: Ensino Médio. Ministério da Educação. Brasília, 2002.

5. DELIZOICOV, Demétrio; ZANETIC, João. A proposta de interdisciplinaridade e o seu impacto no ensino municipal de $1^{\circ}$ grau. In: PONTUSCHKA, Nídia Nabis (Org.). Ousadia no diálogo. São Paulo: Loyola, 1993.

6. FAZENDA, Ivani. Práticas interdisciplinares na escola. 4. ed. São Paulo: Cortez, 2000.

7. FREIRE, Paulo. Pedagogia do Oprimido. 49. ed. Rio de Janeiro: Paz e Terra, 2005.

8. GOMES, Ana Laudelina F. (et al.). Avaliação diagnóstica: a situação do ensino de Sociologia na escola de nível médio no Rio Grande do Norte/Brasil. Revista Eletrônica Inter-Legere. $\mathrm{N}^{\circ} 3$, Jul/Dez, 2008.

9. MORIN, Edgar. Articular os saberes. In: ALVES \& GARCIA (Orgs.). O sentido da escola. Rio de Janeiro: DP\&A, 1999.

10. PIERSON et al. Uma experiência interdisciplinar na formação inicial de professores. Revista Eletrônica Interaç̧ões. n 9, 2008.

11. PERNAMBUCO, Marta Maria C. A. Quando a troca se estabelece: a relação dialógica. In: PONTUSCHKA, Nídia Nabis (Org.). Ousadia no diálogo. São Paulo: Loyola, 1993.

12. ZABALA, Antoni. A prática educativa: como ensinar. Porto Alegre: Artmed, 1998. 